\title{
ERECTOR SPINAE PLANE BLOCK: WHEN PARAVERTEBRAL BLOCK IS NOT AN OPTION
}

\author{
P.H. Andrade Filho ${ }^{1}$, D.D.E. Melo Sousa ${ }^{1}$, L. Gama Costa da ${ }^{1}$, Y. Pinto Nunes ${ }^{1}$, J.M. \\ Silva Junior ${ }^{1,2}$. \\ ${ }^{1}$ IAMSPE - State Civil Servant's Hospital of São Paulo, Department of Anesthesia, São Paulo, Brazil. \\ ${ }^{2}$ ICHC-FMUSP - Faculty of Medicine of the University of São Paulo, Division of Anesthesiology, São Paulo, Brazil.
}

\section{Background and Ains}

The accomplishment of paravertebral block requires integrity of the parietal pleura and it should be avoided in cases of pleural empyema due to the risk of dissemination of the infection to the central nervous system. We present a case in which the erector spinae plane block (ESPB) was chosen as ananalgesic alternative to videothoracoscopic pulmonary decortication.

\section{Methods}

75 years old, male, $64 \mathrm{~kg}$, hypertensive and smoker, with pleural empyema was scheduled to perform videothoracoscopic pulmonary decortication. Considering the contraindications to execute the paravertebral block, the anesthetic team decided to perform an ESPB for postoperative analgesia.

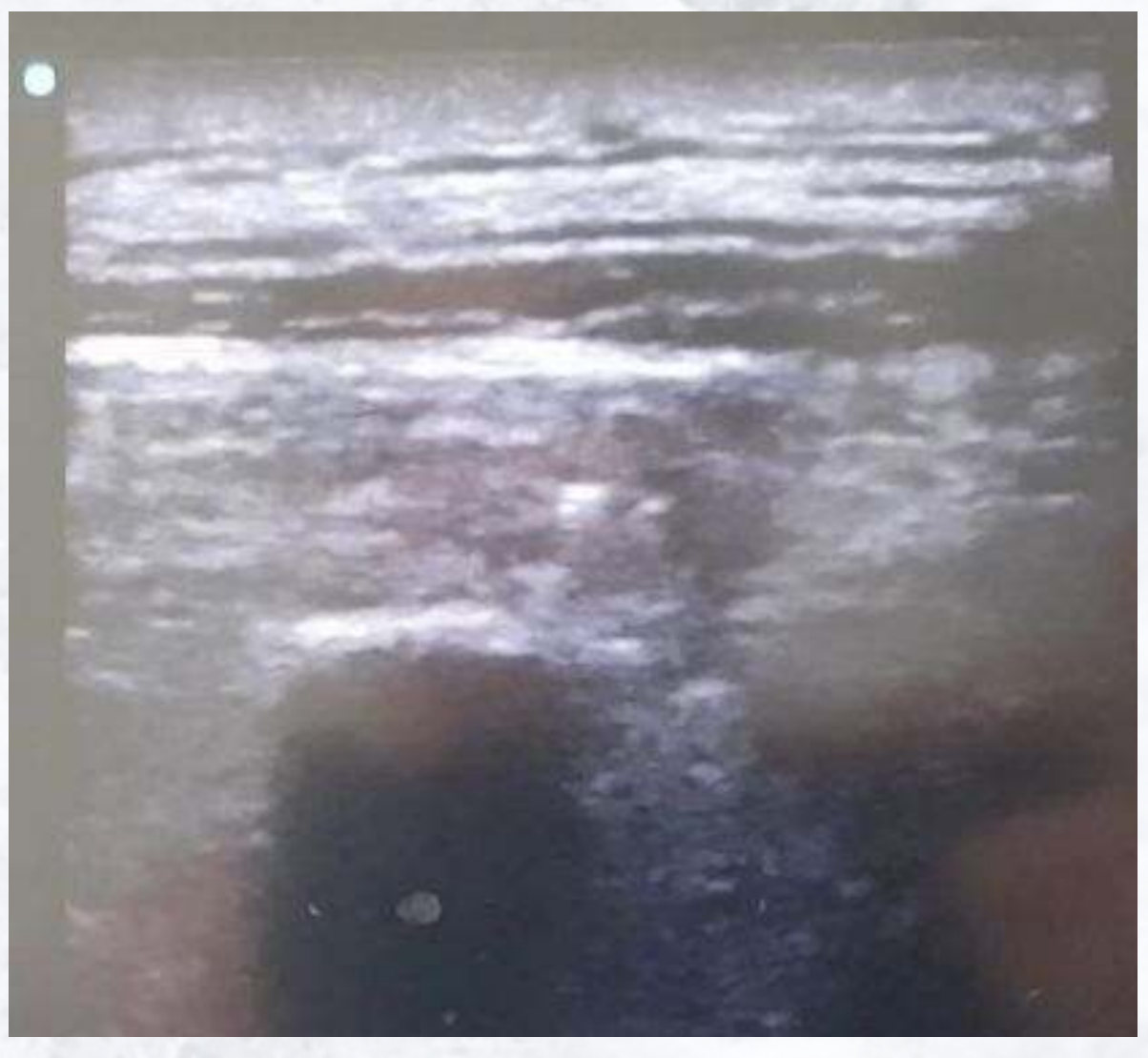

At the end of the surgical procedure, with patient still in lateral decubitus, under general anesthesia, ultrasound guided ESPB was performed at T5 level with $20 \mathrm{~mL}$ of Ropivacaine $0.375 \%$ plus 50 mcg of Clonidine. After extubation, the patient awoke without complaints and was referred to intensive care unit (ICU). After 3 hours in ICU, the patient assigned grade 2 on numerical scale of pain intensity. The first request for complementary analgesia occurred after 5 hours in ICU.

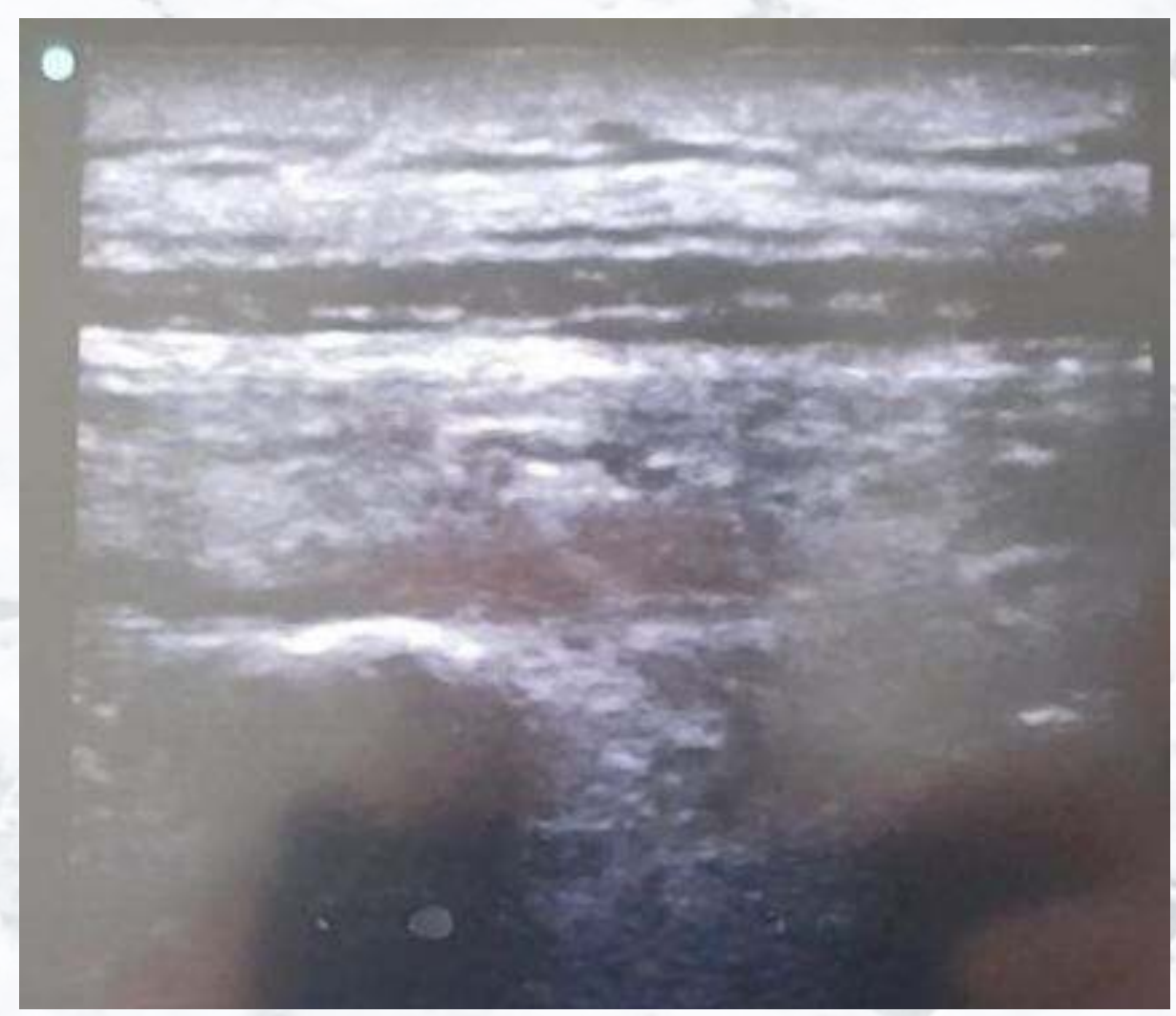

Image 2: Thoracic ultrasound scan after the ESPB;

\section{Conclusion}

In patients with contraindication to paravertebral block due to parietal pleural damage or empyema, ESPB represents a regional anesthesia alternative in postoperative analgesia for thoracic surgeries. 